\title{
Biomimetic enterobactin analogue mediates iron-uptake and cargo transport into $E$. coli and $P$. aeruginosa
}

\author{
Robert Zscherp, ${ }^{[a], \#}$ Janetta Coetzee, ${ }^{[b],[c], \#}$ Johannes Vornweg, ${ }^{[a]}$ Jörg Grunenberg, ${ }^{[a]}$ Jennifer \\ Herrmann, ${ }^{[b],[c]}$ Rolf Müller ${ }^{[b],[c]}$ and Philipp Klahn*,[a] ${ }^{[}$ \\ [a] R. Zscherp, J. Vornweg, Prof. Dr. J. Grunenberg, Dr. P. Klahn* \\ Institute of Organic Chemistry \\ Technische Universität Braunschweig \\ Hagenring 30, D-38106 Braunschweig, Germany \\ E-mail: p.klahn@tu-bs.de, (DORC ID: 0000-0003-4713-2345 \\ [b] J. Coetzee, Dr. J. Herrmann, Prof. Dr. R. Müller \\ Department for Microbial Natural Products \\ Helmholtz Institute for Pharmaceutical Research Saarland (HIPS), Helmholtz Center for Infection Research Department of Pharmacy at Universität des \\ Saarlandes, Campus Building E 8.1, D-66123 Saarbrücken, Germany \\ [c] German Center for Infection Research (DZIF), Site Hannover-Braunschweig, Germany \\ \# $\quad$ Authors contributed equally.
}

\begin{abstract}
The design, synthesis and biological evaluation of the artificial enterobactin analogue Ent $\mathbf{K L}_{\mathrm{L}}$ and several fluorophore-

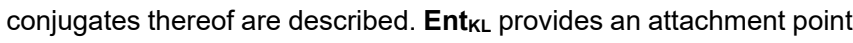
for cargos such as fluorophores or antimicrobial payloads. Corresponding conjugates are recognized by outer membrane siderophore receptors of Gram-negative pathogens and retain the natural hydrolyzability of the tris-lactone backbone, known to be key for uptake into the cytosol. Initial density-functional theory (DFT) calculations of the free energies of solvation $(\Delta G(\mathrm{sol}))$ and relaxed Fe$\mathrm{O}$ force constants of the corresponding [Fe-EntкL] ${ }^{3-}$ complexes indicated a similar iron binding constant compared to natural enterobactin (Ent). The synthesis of Ent $_{\mathrm{KL}}$ was achieved via an iterative assembly based on a 3-hydroxylysine building block over 14 steps with an overall yield of $3 \%$. A series of growth recovery assays under iron-limiting conditions with Escherichia coli and Pseudomonas aeruginosa mutant strains that are defective in natural siderophore synthesis revealed a potent concentration-dependent growth promoting effect of Ent $\mathrm{KL}$ similar to natural Ent. Additionally, four cargo-conjugates differing in molecular size were able to restore growth of $E$. coli indicating an uptake into the cytosol. $P$. aeruginosa displayed a stronger uptake promiscuity as six different cargoconjugates were found to restore growth under iron-limiting conditions. Imaging studies utilizing BODIPYFL-conjugates, demonstrated the ability of EntKL to overcome the Gram-negative outer membrane permeability barrier and thus deliver molecular cargos via the bacterial iron transport machinery of $E$. coli and $P$. aeruginosa.
\end{abstract}

\section{Introduction}

The development of bacterial resistance towards antimicrobial drugs is an intrinsic part of bacterial evolution and this, in turn, necessitates the continuous development of novel drugs able to kill these life-threatening multi-drug resistant human pathogens. ${ }^{[1-}$ 3] Facing the current spread of bacterial resistance against clinically used antibiotics, the development of novel antimicrobial drugs and innovative concepts is of vast importance to counteract this serious threat for public health. ${ }^{[1,4,5]}$

Four of the six ESKAPE pathogens, ${ }^{[6,7]}$ represent bacterial species considered as significant threat for public health due to a very high occurrence of multi-drug resistance, are Gram-negative bacteria. In addition, the pathogens recently prioritized by the
WHO with a critical, high or medium need for the development of novel antimicrobial drugs are primarily Gram-negative bacteria, including $\beta$-lactam-resistant Escherichia coli and Pseudomonas aeruginosa or fluoroquinolone-resistant Salmonella and Shigella species. ${ }^{[8]}$ However, the development of novel antimicrobial drugs against Gram-negative bacteria is challenging, not only due to the presence of drug exporters as also found in Gram-positive bacteria, but because many antibacterial compounds fail to overcome the Gram-negative outer membrane. As a consequence, many potential drugs displaying antibacterial activity against Gram-positive bacteria remain inactive against Gram-negative bacteria, although their biological targets are generally present, as they fail to translocate over the cell envelope barrier. ${ }^{[9]}$

An innovative approach to enable translocation of antimicrobial drugs or reporter molecules over the Gram-negative cell envelope barrier and to develop novel antimicrobial drugs against these pathogens is the conjugation and hybridization with siderophores..$^{[4,10,11]}$ Siderophores are small molecule iron chelators ${ }^{[12,13]}$ produced and secreted by bacteria to ensure their supply with iron, an essential growth factor for all bacteria. Beyond iron uptake, siderophores have multiple other biological functions, ${ }^{[14-16]}$ e.g. they are important virulence factors contributing to pathogenesis of bacteria. ${ }^{[15,17]}$ After coordination of $\mathrm{Fe}(\mathrm{III})$, the resulting ferri-siderophores are recognized by specific siderophore receptors, transmembrane proteins embedded in the outer membrane, and are actively transported into the cytosol of bacteria. ${ }^{[4,18-21]}$ Siderophore drug conjugates can enter bacterial cells via the same pathway through siderophore receptor mediated uptake..$^{[4,22-31]}$ The general concept of this Trojan Horse approach is derived from natural antetypes. The sideromycins, ${ }^{[32]}$ such as albomycins ${ }^{[33-35]}$ or the microcins $E 492^{[36-39]}$ and $\mathrm{H} 47^{[40]}$ are utilized by different bacteria to defend their ecological niche against competing bacteria. These natural siderophore drug conjugates reveal a remarkable increase in antibacterial activity compared to the parental free antibiotics. Inspired by this natural concept researchers have developed artificial siderophore drug conjugates based on synthetically modified siderophore analogues, ${ }^{[41-54]}$ leading to active drug accumulation and tremendously increased antibacterial activity compared to the parental drugs. ${ }^{[41,42,47]}$ Furthermore, siderophore drug conjugates can expand the activity of Gram-positive-only drugs towards Gram-negative pathogens. ${ }^{[49,50,55,56]}$ 

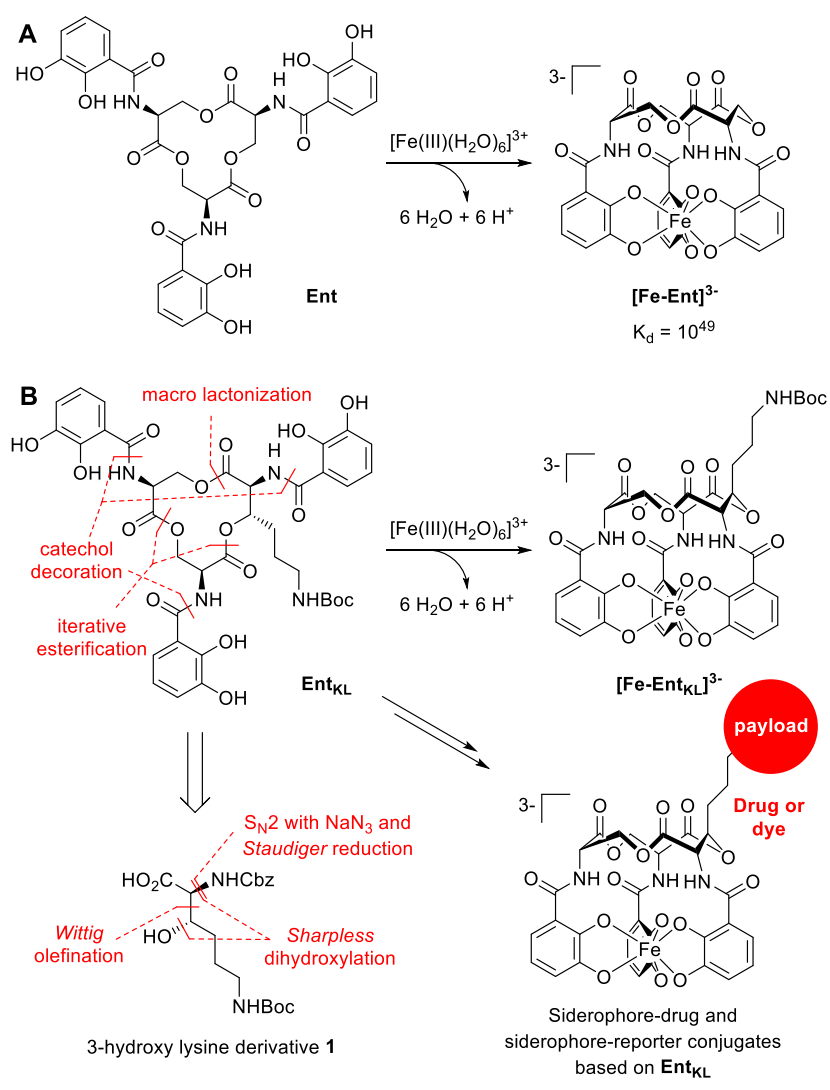

Scheme 1. A: Structures of enterobactin (Ent) and ferri-enterobactin ([Fe-Ent $\left.]^{3-}\right)$; B: Retrosynthetic analysis and design concept of EntKL.

Additionally, this strategy allows for the design of narrowspectrum antibiotics, ${ }^{[10,48,56]}$ selectively targeting specific virulent pathogens, thereby reducing the selection pressure on the bacterial resistome. Importantly, the siderophore- $\beta$-lactam hybrid Cefiderocol developed by Shionogi Pharmaceuticals was recently approved by the FDA for the treatment of pneumonia caused by Gram-negative bacteria. ${ }^{[57]}$

In this context, the tris-catechol siderophore enterobactin (Ent, Scheme $1, \mathrm{~A})^{[13]}$ displaying an extraordinarily high $\mathrm{Fe}(\mathrm{III})$ binding constant $\left(\mathrm{K}_{\mathrm{d}}=10^{49}\right)^{[58,59]}$ as well as its glycosylated derivatives, the salmochelins ${ }^{[60]}$ evading lipocalin-2 inactivation, ${ }^{[61,62]}$ are of high interest. Ent and salmochelins are biosynthesized by Gramnegative bacteria of the family Enterobacteriaceae, such as E. coli, Klebsiella pneumonia, Salmonella typhimurium, Yersinia enterocolitica and Shigella flexneri, to ensure their iron supply. ${ }^{[63]}$ However, Ent has also been found to be produced by Grampositive Streptomyces species ${ }^{[64]}$ and it serves as a xenosiderophore for the opportunistic human pathogen $P$. aeruginosa, where internalization is mediated by the outer membrane siderophore receptor PfeA.$^{[65-68]}$ Ent and salmochelins also play a crucial role during infection ${ }^{[16,69]}$ and they have been demonstrated to sequester iron from human transferrin. ${ }^{[15,17]}$

Previously reported artificial Ent analogues used for the development of siderophore drug conjugates or siderophorebased imaging tools ${ }^{[70,71]}$ were based on modifications at one of the catechol units ${ }^{[1,42,45,48,51,72]}$ or the natural tris-serine lactone backbone was substituted by artificial moieties to generate an attachment point for payloads in the backbone of the siderophore. ${ }^{[47,73-75]}$ Although a co-crystal structure of [Fe-Ent $]^{3-}$ with its $E$. coli siderophore receptors of $\mathrm{FepA}^{[76,77]}$ and IroN ${ }^{[77-79]}$ is not available, recognition of [Fe-Ent] $]^{3-}$ at other proteins such as FeuA, ${ }^{[80-82]} \mathrm{VctP}{ }^{\left[{ }^{83]}\right.} \mathrm{PfeA}^{[68]}$ or lipocalin-2 ${ }^{[80]}$ suggests that the attachment of larger payloads at the catechol units might interfere with [Fe-Ent] $]^{3-}$ receptor recognition.

Therefore, we envisaged the synthesis of the novel, biomimetic enterobactin analogue EntKL (Scheme 1, B). Our synthesis is based on the incorporation of the 3-hydroxy lysine derivative 1 into Ent backbone, aiming to generate an attachment point for antimicrobial payloads in the backbone out of the recognition site of the siderophore and simultaneously retain the natural hydrolyzability of the tris-lactone backbone. ${ }^{[51,84]}$

\section{Results and Discussion}

Retrosynthetically, the final siderophore should be derived from a modified asymmetric tris-lactone backbone by decoration with catechol units via amide coupling (Scheme 1, B). As the tintemplate mediated trans-esterification approach utilized earlier, by Shanzer, ${ }^{[85,86]}$ later by Guiterrez ${ }^{[87]}$ and Raymond ${ }^{88]}$ for the synthesis of the enterobactin tris-serine lactone backbone, leads exclusively to the formation of the thermodynamic, symmetric product, it is not applicable for the synthesis of the envisaged asymmetric tris-lactone backbone. Therefore, we decided to follow an approach of iterative assembly of a linear trimer containing the 3-hydroxy lysine derivative 1 with subsequent macro lactonization as used in the early synthesis of Ent by Corey, ${ }^{[89]}$ Rastetter $^{[90]}$ and Rogers ${ }^{[91]}$ in order to generate the desired asymmetric backbone of Ent $\mathrm{KL}_{\mathrm{L}}$. In order to estimate if the envisaged substituent at the asymmetric tris-lactone backbone would negatively impact the solution thermodynamics and/or the kinetic stability of the $\mathrm{Fe}(\mathrm{III})$ complex [Fe-EntKL ${ }^{3-}$, we computed the free energies of solvation $\Delta G($ sol) as well as the relevant (relaxed) $\mathrm{Fe}-\mathrm{O}$ force constants for [Fe-Ent] ${ }^{3-}$ and two stereoisomers of [Fe-EntKL] $]^{3-}$ bearing an axial or equatorial substituent (Table 1) following the protocol of Baramov et al. ${ }^{[92]}$ (see $\mathrm{SI}$ ). In a first step, we tried to reproduce the experimentally well-known free energy of complexation $(\Delta G(\mathrm{sol})$ : $\left.66.8 \mathrm{kcal} / \mathrm{mol}^{[58,59]}\right)$ for [Fe-Ent $]^{3-}$.

Table 1. Calculated $\Delta \mathrm{G}(\mathrm{sol})$ and averaged, relaxed force constants of the $\mathrm{Fe}-\mathrm{O}$ single bonds of $[\mathrm{Fe}-E n t]^{3-}$, [Fe-Ent $\left.\mathrm{KL}_{\mathrm{L}}(\mathrm{ax})\right]^{3-a n d}\left[\mathrm{Fe}-\mathrm{Ent}_{\mathrm{KL}}(\mathrm{eq})\right]^{3-}$

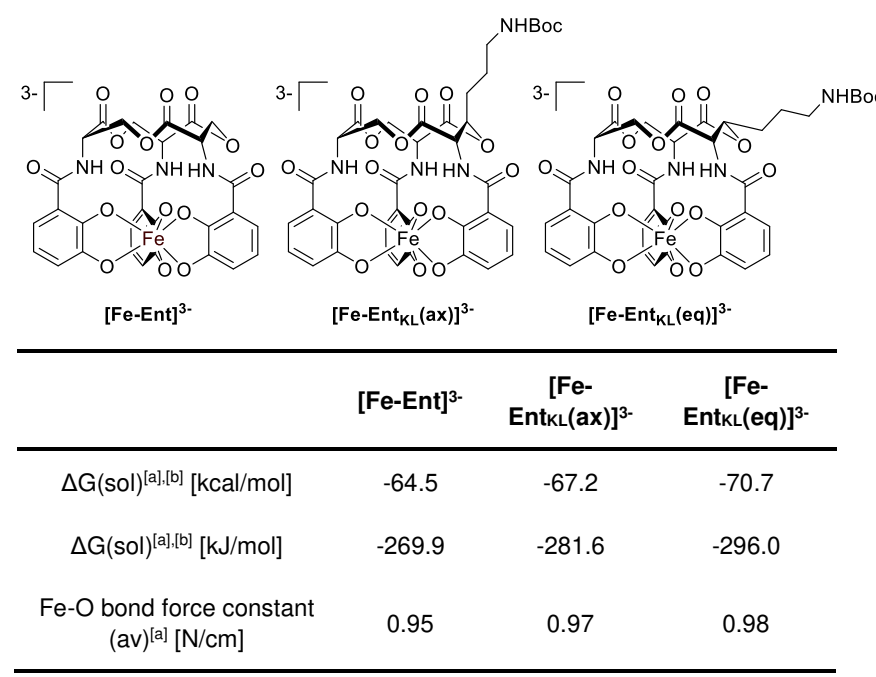

[a] Computed for DMSO as solvent. [b] Separate consideration of all hydronium ions. 
Our calculated value of $64.1 \mathrm{kcal} / \mathrm{mol}$ for $\Delta \mathrm{G}(\mathrm{sol})$ [Fe-Ent] ${ }^{3-}$ is very close to the literature reference ${ }^{[58,59]}$ positively validating our applied in silico procedure. Interestingly, the artificial ferrienterobactin analogues seem to be even better iron binders than the unsubstituted [Fe-Ent] $]^{3-}$ by several $\mathrm{kcal} / \mathrm{mol}$. Furthermore, the value for $\left[\mathrm{Fe}-\mathrm{Ent}_{\mathrm{KL}}(\mathrm{eq})\right]^{3-}$ was calculated to be energetically more favored as compared to $\left[\mathrm{Fe}-\mathrm{Ent}_{\mathrm{KL}}(\mathbf{a x})\right]^{3-}$ by a value of $3.5 \mathrm{kcal} / \mathrm{mol}$.Nevertheless, the absolute values need to be considered with caution and we hypothesize that both artificial enterobactin analogues, $\operatorname{Ent}_{\mathrm{KL}}(\mathbf{e q})$ and $\operatorname{Ent}_{\mathrm{KL}}(\mathbf{a x})$, lead to complexes which are at least of similar thermodynamic stability compared to [Fe-Ent $]^{3-}$ and that there is no significant energetical advantage of one analogue over the other. While siderophore $\mathrm{Fe}$ (III) complexes are thermodynamically very stable, they are kinetically labile. This is in contrast to, for example, their chromic counterparts, which are both thermodynamically and kinetically stable. In order to find out if this kinetic lability holds true also for our artificial ferri-enterobactin analogues, we calculated the relaxed $\mathrm{Fe}-\mathrm{O}$ force constants, a method which was recently successfully applied in several other weakly bound systems.

According to our computational results, all three complexes seem to be kinetically labile with relaxed Fe-O force constants well below $1 \mathrm{~N} / \mathrm{cm}$ (see Table 1), indicating very weak bonds with less or no covalency. ${ }^{[93-97]}$ (Note, that the averaged $\mathrm{Cr}-\mathrm{O}$ value for [CrEnt] ${ }^{3-}$ is $1.25 \mathrm{~N} / \mathrm{cm}$; unpublished results J.G.).Furthermore, our calculated $\mathrm{Fe}-\mathrm{O}$ values are very similar. In summary, all three complexes seem to be kinetically labile, while being thermodynamically stable, as found earlier for [FeEnt] $]^{3-}$ by Raymond and co-workers. ${ }^{\text {98, } 99]}$

Thus, expecting no negative impact of an axial backbone substituent on the $\mathrm{Fe}(\mathrm{III})$ complex stability, we developed a robust, scalable synthetic route to the required 3-hydroxy lysine derivative 1 starting from commercially available 4-aminobutanol (2) as outlined in Scheme 2. A sequence of Boc protection, Swern oxidation of the resulting $\mathrm{N}$-Boc-4-aminobutanol (3) to aminal 4 and final Wittig olefination in presence of methyl (triphenylphosphoranylidene) acetate (5) at $100^{\circ} \mathrm{C}$ led to formation of the $E$-configured $\alpha, \beta$-unsaturated methyl ester 6 in excellent diastereoselectivity of $E: Z=100: 1$ and $89 \%$ yield over 3 steps with only a single chromatographic purification step being required.

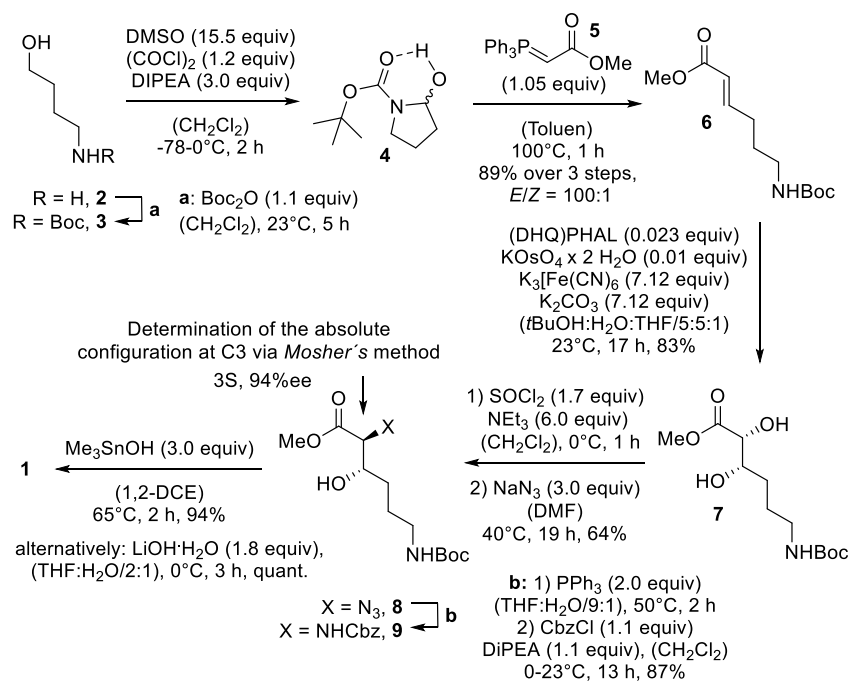

Scheme 2. Synthesis of 3-hydroxy lysine derivative 1.
An asymmetric Sharpless dihydroxylation using AD-mix- $\alpha$ finally gave diol 7 in $83 \%$ yield. The formation of the corresponding cyclic sulfite in the presence of thionyl chloride and triethyl amine at $0^{\circ} \mathrm{C}$ and subsequent $\alpha$-inversion in the presence of sodium azide afforded a-azido methyl ester 8 in $64 \%$ yield. At this step the absolute configuration at the C3 position introduced by the Sharpless dihydroxylation was determined to be S-configured with an enantiomeric excess of 94\%ee using Mosher's method. ${ }^{[100]}$

Finally, a Staudinger reduction and subsequent $\mathrm{Cbz}$ protection generated the methyl ester 9 in $87 \%$ yield, which was saponified in the presence of trimethyltin hydroxide in 1,2-dichloro ethane at $65^{\circ} \mathrm{C}$ using Nicolaou's protocol[101] yielding the desired 3-hydroxy lysine derivative 1 in $94 \%$.

With 1 in hands, we achieved the assembly of the linear trimer 17 as outlined in Scheme 3. First, the 2-methylanthraquinyl ester 11 was formed with 2-bromomethylanthraquinone $\mathbf{1 0}(\mathrm{MaqBr})$ in the presence of $\mathrm{DBU}$ in $55 \%$ yield. ${ }^{[90]} \mathrm{A}$ two times consecutive sequence of Steglich esterification with Cbz-Ser(TBS)-OH 12 and subsequent desilylation in the presence of a mixture of aqueous, concentrated HF solution and TBAF led to the Maq-protected linear trimer 16 obtained in $64 \%$ yield over 4 steps.

Ester 16 was then photolytically cleaved at $360 \mathrm{~nm}$ in the presence of $\mathrm{N}$-methyl morpholine (NMM) in a mixture of isopropanol and chloroform giving the unprotected linear trimer 17 as precursor for the backbone cyclization in $65 \%$ yield. ${ }^{[90]}$

As expected for the formation of a 12-membered ring with several axial substituents, the cyclization of $\mathbf{1 7}$ to the tris-lactone $\mathbf{1 8}$ was challenging. The activation of the carboxylic acid via several reagents predominantly led to elimination under formation of the corresponding dihydro amino acid (Table 2).

After extensive screening of different methods for the macro lactonization, a first success with a low yield of $13 \%$ was achieved using Shiina's reagent ${ }^{[102]}$ (Entry 1, Table 2). Any other screened coupling reagent such as different carbodiimides, PyBOP, $\mathrm{T}_{3} \mathrm{P}$ (propylphosphonic anhydride) or Yamaguchi's reagent ${ }^{[103]}$ could not furnish the macro lactonization, favouring elimination. The activation of the alcohol through intramolecular Mitsunobu reaction gave similarly a low yield of $14 \%$ (Entry 2, Table 2). Finally, the highest yield of $50 \%$ for tris-lacton 18 was obtained using Gerlach's modification ${ }^{[104]}$ of the Corey-Nicolaou macro lactonization, ${ }^{105]}$ first formation of the intermediate thioester using Corey's disulfane and subsequent silver-catalyzed cyclization at $23^{\circ} \mathrm{C}$ in benzene (Entry 3, Table 2).

Table 2. Selected conditions for the cyclization of the linear trimer 17.

\begin{tabular}{|c|c|c|}
\hline Entry & Conditions & Result \\
\hline 1 & $\begin{array}{l}\text { MNBA }\left(5.0 \text { eq), DMAP }\left(8.0 \text { eq), }\left(\mathrm{CH}_{2} \mathrm{Cl}_{2}\right), 0-23^{\circ} \mathrm{C} \text {, }\right.\right. \\
20 \mathrm{~h}\end{array}$ & $13 \%[\mathrm{a}]$ \\
\hline 2 & $\mathrm{PPh}_{3}(1.5 \mathrm{eq}), \mathrm{DIAD}(1.3 \mathrm{eq}),(\mathrm{THF}), 0-23^{\circ} \mathrm{C}, 24 \mathrm{~h}$ & $14 \%[a]$ \\
\hline 3 & $\begin{array}{l}\text { 1) Corey's disulfane }{ }^{[89]}(1.4 \mathrm{eq}), \mathrm{PPh}_{3}(1.4 \mathrm{eq}) \text {, } \\
\left.\left(\mathrm{CH}_{2} \mathrm{Cl}_{2}\right), 23^{\circ} \mathrm{C}, 10 \mathrm{~min} ; 2\right) \mathrm{AgBF}_{4}(5.0 \mathrm{eq}),(\mathrm{PhH}) \text {, } \\
25^{\circ} \mathrm{C}, 16 \mathrm{~h}\end{array}$ & $5-50 \%{ }^{[a],[b]}$ \\
\hline 4 & $\begin{array}{l}\text { 1) } 2,2^{\prime}-\text {-Dipyridyldisulfide }(1.4 \mathrm{eq}), \mathrm{PPh}_{3}(1.4 \mathrm{eq}) \text { in } \\
\left(\mathrm{CH}_{2} \mathrm{Cl}_{2}\right), 30^{\circ} \mathrm{C}, 90 \mathrm{~min} \text {; 2) } \mathrm{AgOAc}(2.0 \mathrm{eq}),(\mathrm{PhH}) \text {, } \\
30^{\circ} \mathrm{C}, 3 \mathrm{~h}\end{array}$ & $32 \%{ }^{[a]}$ \\
\hline
\end{tabular}

[a] Elimination. [b] Bad reproducibility. 

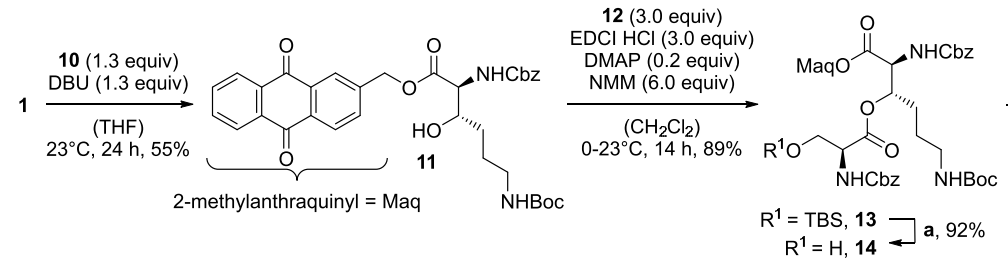

12 (1.1 equiv)

DMAP (0.1 equiv) $\mathrm{CbzHN} \mathrm{R}^{2} \mathrm{NHCbz}$ NMM (2.2 equiv) ( $0-23^{\circ} \mathrm{C}, 3 \mathrm{~h}, 94 \%$$$
\text { (1) }
$$$$
\text { ( } 23,3 \mathrm{~h}, 94 \%
$$

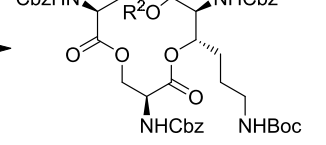
$\mathrm{R}^{2}=$ Maq, $\mathrm{R}^{1}=\mathrm{TBS}, 15$
$\mathrm{R}^{2}=$ Maq, $\mathrm{R}^{1}=\mathrm{H}, 16$
$\mathrm{R}^{2}=\mathrm{H}^{2}, 88 \%$
$\mathrm{~b}, 65 \%$
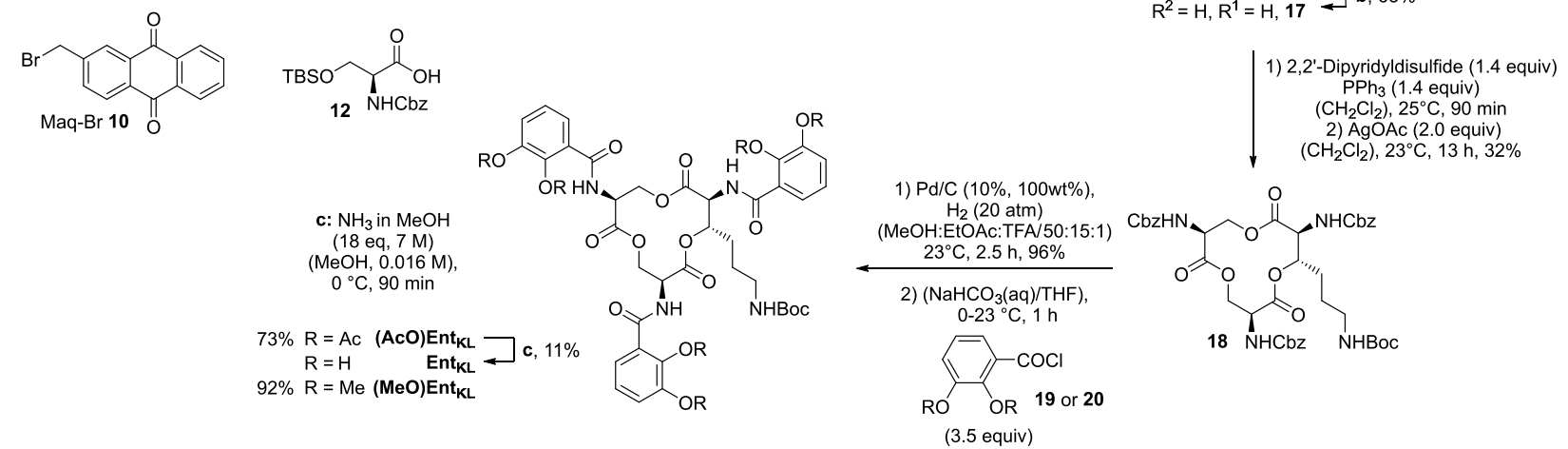

Scheme 3. Assembly of a linear trimer, cyclization and final catechol decoration.

However, as the yield of this reaction was hardly reproducible, we finally applied 2,2'-dipyridyldisulfide to form the intermediate thioester and furnished macro lactonization in the presence of silver acetate giving 32\% yield of the desired tris-lactone 18 reliably (Entry 4, Table 2). The final quantitative, hydrogenolytic $\mathrm{Cbz}$ deprotection required $20 \mathrm{~atm}$ of hydrogen gas in a mixture of methanol, ethyl acetate and TFA. Subsequent acylation under Schotten-Baumann conditions with 2,3-diacetoxybenzoic acid chloride $\mathbf{1 9}$ or 2,3-dimethoxybenzoic acid chloride 20, respectively, led to the formation of (AcO)Ent $\mathrm{KL}_{\mathrm{KL}}$ and $(\mathrm{MeO}) \mathrm{Ent}_{\mathrm{KL}}$. Ent $_{\mathrm{KL}}$ could be obtained in low yield from (AcO)Ent $\mathrm{KL}_{\mathrm{KL}}$ by mild saponification in diluted methanolic ammonia. However, as it has been reported that acetylated siderophore-prodrugs can be activated in situ and are favorable to prevent the inactivation of catecholates by enzymatic methylation, ${ }^{[47,73,106,107]}$ we employed (AcO)Ent $\mathrm{KL}_{\mathrm{KL}}$ as siderophore-prodrug and (MeO)Ent $\mathrm{KL}_{\mathrm{KL}}$ as starting point for the synthesis of corresponding negative probes, unable to bind iron or mediate uptake in our approach. In order to determine if the synthesized enterobactin derivatives are internalized by $E$. coli and $P$. aeruginosa during iron limitation, growth recovery assays were done with mutant strains that lack the ability to biosynthesize siderophores, and therefore require external siderophores to be able to grow under iron-limiting conditions. Importantly, iron-limiting conditions are typically found in vivo at the site of infections being part of the host immune response to prevent bacterial growth. ${ }^{[57,108,109]} \mathrm{E}$. coli K-12 $\triangle$ entA grew to $\mathrm{OD}_{600} \approx 0.35$ in $50 \% \mathrm{MHB}$ II medium $\left(37^{\circ} \mathrm{C}, \mathrm{t}=24 \mathrm{~h}\right)$, and this value decreased to $<0.05$ when $200 \mu \mathrm{M}$ 2,2'-bipyridine (DP) was added to the media in order to simulate iron-limiting conditions. Low-micromolar concentrations of Ent restored growth, and the $E$. coli cultures reached $\mathrm{OD}_{600} \approx 0.1,0.15$ and 0.3 in the presence of $1.0 \mu \mathrm{M}, 10 \mu \mathrm{M}$ and $15 \mu \mathrm{M}$ Ent, respectively (Figure 1, A).

Intriguingly, the addition of $(\mathrm{AcO}) \mathrm{Ent}_{\mathrm{KL}}$ led to restore the growth of $E$. coli K-12 $\triangle$ entA in the presence of DP in a concentration dependent-manner and with a similar efficiency as the natural siderophore Ent (Figure 1, A and B). A significant increase in growth was observed starting at $1 \mu \mathrm{M}$ concentration, while at
$10 \mu \mathrm{M}$ and $15 \mu \mathrm{M}$ the cultures grew to $\mathrm{OD}_{600} \approx 0.15$ and 0.3 , respectively, indicating the ability of (AcO)Ent KL $_{\text {L }}$ to be internalized into the cytosol of $E$. coli. Similarly, $P$. aeruginosa K648 $\Delta p v d / p c h$ grew to $\mathrm{OD}_{600} \approx 0.4\left(37^{\circ} \mathrm{C}, \mathrm{t}=24 \mathrm{~h}\right)$ and this value decreased to $<0.25$ in the presence of $600 \mu \mathrm{M}$ DP. Supplementation of the ironreduced growth medium with $1.0 \mu \mathrm{M}$ of Ent resulted in the restoration of $P$. aeruginosa growth to $\mathrm{OD}_{600} \approx 0.35$ (Figure $1, \mathrm{D}$ ). At higher concentrations of Ent of $10 \mu \mathrm{M}$ and $15 \mu \mathrm{M}$ the growth promoting response was even exceeding the growth in absence of $\mathrm{DP}$, with $P$. aeruginosa $\mathrm{K} 648 \Delta p v d / p c h$ growing to $\mathrm{OD}_{600} \approx 0.5$ and 0.6, respectively. Again, (AcO)Ent $\mathrm{KL}_{\mathrm{KL}}$ was also able to restore the growth of $P$. aeruginosa $\mathrm{K} 648 \Delta p v d / p c h$ under iron-limiting conditions in a concentration-dependent manner (Figure 1, D and $\mathrm{E})$. While the growth promoting effect of $(\mathrm{AcO}) \mathrm{Ent}_{\mathrm{KL}}$ at a concentration of $1.0 \mu \mathrm{M}$ was slightly smaller compared to Ent, the growth promoting was clearly surpassing the effect of Ent at $10 \mu \mathrm{M}$. In contrast to the uptake of Ent in E. coli, Ent never reaches the cytosol of $P$. aeruginosa as iron release takes place in the periplasm through cleavage of the siderophore backbone by the periplasmic esterase PfeE. ${ }^{[110]}$ This indicates that the compounds are accepted as substrates by PfeE. As expected, the permethylated probe $(\mathrm{MeO}) \mathrm{Ent}_{\mathrm{KL}}$, was not able to restore growth of neither $E$. coli K-12 $\Delta$ entA nor $P$. aeruginosa K648 $\Delta p v d / p c h$ (Figure 1, C and F). Next, we synthesized a series of cargoconjugates of (AcO)Ent $\mathrm{KL}_{\mathrm{L}}$ and $(\mathrm{MeO}) \mathrm{Ent}_{\mathrm{KL}}$ attaching fluorophores and dyes that differ in their size in order to investigate whether $(\mathbf{A c O})$ Ent $_{\mathrm{KL}}$ is able to deliver different cargo molecules to $E$. coli and $P$. aeruginosa.

Therefore, we cleaved the Boc group at the amino handle in the presence of TFA in dichloromethane and reacted the resulting free amine in the presence of $\mathrm{N}$-hydroxy succinimide (NHS) esters of the corresponding fluorophores and dyes (SulfoCy5-

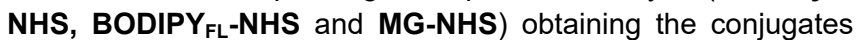
(AcO)Ent $\mathrm{KL}_{\mathrm{KL}}$-BODIPY $\mathrm{FL}, \quad(\mathrm{AcO})$ Ent $_{\mathrm{KL}}-\mathrm{MG}$ and (AcO)Ent $\mathrm{KL}_{\mathrm{KL}}$ SulfoCy5 as well as their respective negative probes (MeO)Ent $\mathrm{KL}_{\mathrm{L}-\mathrm{BODIPY}} \mathrm{FL}, \quad(\mathrm{MeO}) \mathrm{Ent}_{\mathrm{KL}}-\mathrm{MG}$ and (MeO)Ent $\mathrm{KL}-$ SulfoCy5 in moderate yields as outlined in Scheme 4. 

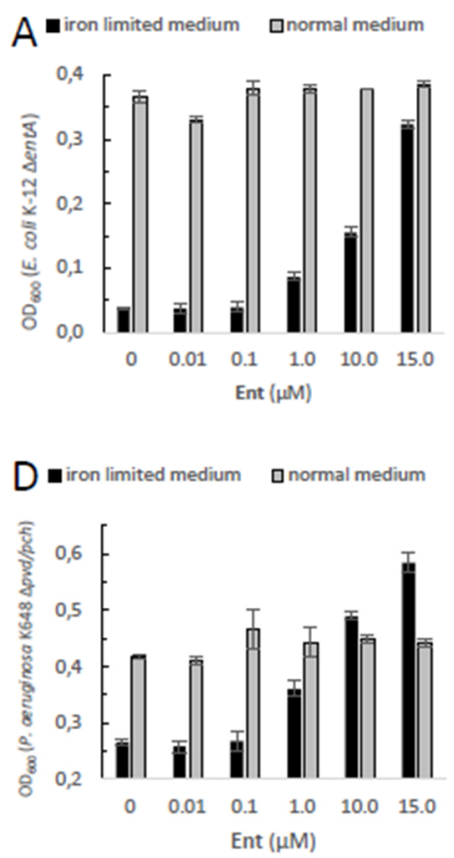
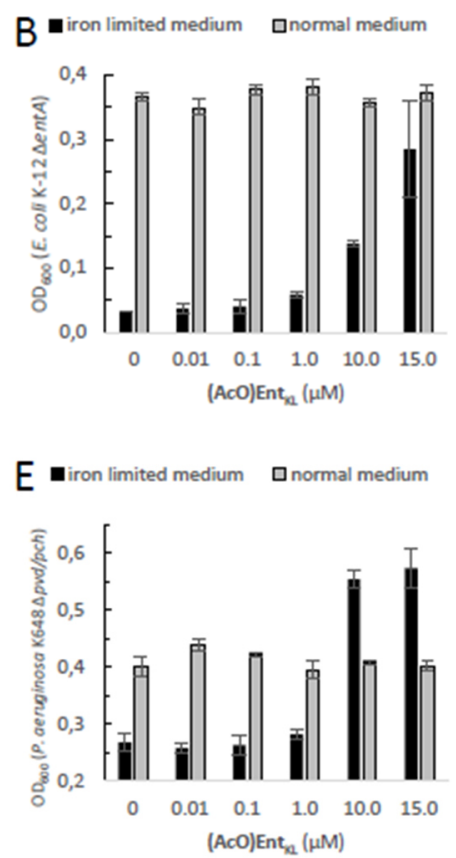
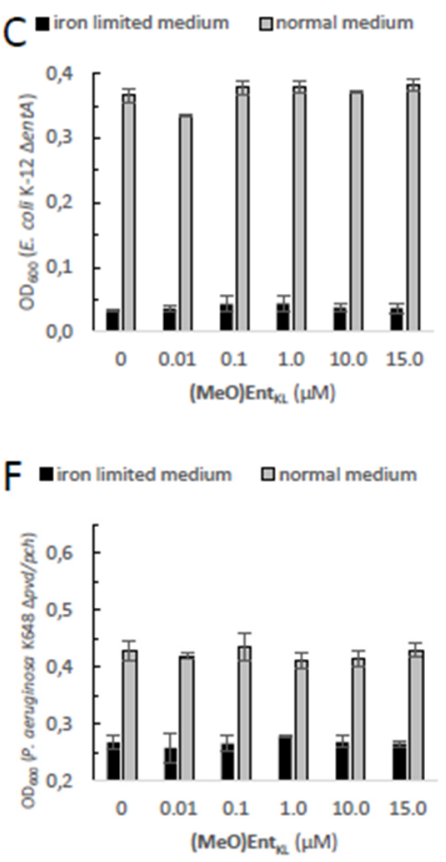

Figure 1. E. coli K-12 $\Delta$ entA and $P$. aeruginosa K648 $\Delta$ pvd/pch growth recovery assays employing Ent in comparison to (AcO)Ent $\mathrm{KL}_{\mathrm{L}}$ and (MeO)Ent $\mathrm{KL}$ (50\% $\mathrm{MHB}$ II, \pm 200 or $600 \mu \mathrm{M}$ DP $\left(2,2^{\prime}\right.$-bipyridine $\left.), t=24 \mathrm{~h}, 37^{\circ} \mathrm{C}\right)$. Gray bars: $\mathrm{OD}_{600}$ of bacteria cultured in the absence of DP. Black bars: $\mathrm{OD}_{600}$ of bacteria cultured in the presence of $200 \mu \mathrm{M}$ (E. coli) or $600 \mu \mathrm{M}$ (P. aeruginosa) DP. A) Ent promotes growth recovery of E. coli. B) (AcO)Ent $\mathrm{KL}_{\mathrm{L}}$ affords growth recovery of E. coli. C) (MeO)EntKL shows no growth recovery of $E$. coli. D) Ent promotes growth recovery of $P$. aeruginosa. E) (AcO)EntKL affords growth recovery of $P$. aeruginosa. $\mathrm{F}$ ) (MeO)Ent $\mathrm{KL}_{\mathrm{KL}}$ shows no growth recovery of $P$. aeruginosa. Each bar indicates the average of three independent replicates (two wells per replicate) and the error bars are the standard deviation of the mean.

Similarly, initial Boc cleavage in the presence of TFA and subsequent installation of a $\mathrm{PEG}_{4}-\mathrm{N}_{3}$ chain via $\mathrm{NHS}$ ester coupling gave access to the corresponding (AcO)Ent $\mathrm{KL}_{\mathrm{L}}-\mathrm{PEG}_{4}-\mathrm{N}_{3}$ and $(\mathbf{M e O})$ Ent $_{\mathrm{KL}}-\mathrm{PEG}_{4}-\mathrm{N}_{3}$. Final copper(I)-mediated azide-alkyne click reaction with alkyne functionalized BODIPYs (BODIPYalkyne and BODIPY $\mathrm{FL}$-alkyne) furnished the conjugates (AcO)Ent $\mathrm{KL}_{\mathrm{LL}}-\mathrm{PEG}_{4}-\mathrm{BODIPY}$ and (AcO)Ent $\mathrm{KL}_{\mathrm{KL}}-\mathrm{PEG}_{4}-\mathrm{BODIPY}_{\mathrm{FL}}$ as well as their respective negative probes $(\mathbf{M e O})$ Ent $_{\mathrm{KL}}-\mathrm{PEG}_{4^{-}}$ BODIPY and (MeO)Ent $\mathrm{KL}_{\mathrm{KL}}-\mathrm{PEG}_{4}-\mathrm{BODIPY}_{\mathrm{FL}}$ in moderate to good

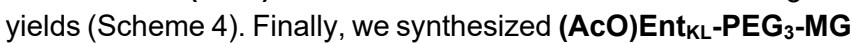
and $(\mathbf{M e O})$ Ent $_{\mathrm{KL}}-\mathrm{PEG}_{3}-\mathbf{M G}$ via a sequence of initial Boc cleavage, installation of a $\mathrm{PEG}_{3}-\mathrm{NHBoc}$ chain via $\mathrm{NHS}$ ester coupling, final Boc cleavage and reaction of the free amine with MG-NHS in moderate yields. When incubating $E$. coli K-12 $\Delta$ entA under iron-limiting conditions with (AcO)Ent $\mathrm{KL}_{\mathrm{L}}-\mathrm{PEG}_{4}$-BODIPY, (AcO)Ent ${ }_{\mathrm{KL}}-\mathrm{PEG}_{4}-\mathrm{BODIPY}_{\mathrm{FL}}, \quad\left(\mathrm{AcO}\right.$ Ent $_{\mathrm{KL}}-\mathrm{BODIPY}_{\mathrm{FL}}$ and $(A c O) E t_{K L}-S u l f o C y 5$ led to a concentration-dependent growth recovery (Figure 2, A-D) clearly indicating the uptake of these cargo-conjugates to the cytosol of $E$. coli. The two conjugates $(\mathrm{AcO}) \mathrm{Ent}_{\mathrm{KL}}-\mathrm{MG}$ and $(\mathrm{AcO}) \mathrm{Ent}_{\mathrm{KL}}-\mathrm{PEG}_{3}-\mathrm{MG}$ bearing a malachite green derivative as cargo molecule did not lead to a growth recovery in E. coli (Figure 2, E and F). Furthermore, high concentrations of $10 \mu \mathrm{M}$ and $15 \mu \mathrm{M}$ seemed to reduce overall growth in E. coli K-12 $\Delta$ entA (Figure 1, E and F) as well as in the E. coli wild-type strain (see Supporting Information: Figure S7 and S8). This might be due to the fact that these compounds are not taken up by the bacteria and therefore, they further reduce the available iron in the surrounding medium.

Although, the malachite green derivative attached within (AcO)Ent ${ }_{\mathrm{KL}}$-MG and (AcO)Ent $\mathrm{KL}_{\mathrm{L}}-\mathrm{PEG}_{3}$-MG has a large diameter of approximately $13.7 \AA$ (extracted from an energy minimized structure by Chem3D ${ }^{\circledR}$ Ultra 15.1.0.144), size seems not to be the exclusive parameter for uptake. In comparison, (AcO)Ent $\mathrm{KL}_{\mathrm{KL}}$ SulfoCy5, bearing the rigid SulfoCy5 fluorophore with a length diameter of approximately $19.9 \AA$ (extracted from an energy minimized structure by $C h e m 3 D^{\circledR}$ Ultra 15.1.0.144) of its indocyanine-backbone, led to a growth recovery under same conditions. Looking at the crystal structure of the enterobactin specific siderophore receptor FepA, ${ }^{[76]}$ the transmembrane pore opening upon recognition of Ent seems to have an elliptical inner diameter between 20-30 A, large enough to harbor any of the reported conjugated discussed here. Therefore, additional parameters beyond size seem to determine the uptake of a bound cargo at the outer membrane receptor. However, size exclusion might still play a role at the $\mathrm{ABC}$-type transporter mediating uptake of hydrolyzed fragments across the inner membrane.

When incubating the conjugates with $P$. aeruginosa K648 $\Delta p v d / p c h$ under iron-limiting media conditions all cargo conjugates led to clear concentration-dependent growth recovery, including (AcO)Ent $\mathrm{KL}_{\mathrm{KL}}-\mathbf{M G}$ and $(\mathrm{AcO}) \mathrm{Ent}_{\mathrm{KL}}-\mathbf{P E G}_{3}-\mathbf{M G}$, indicating the uptake of these cargo-conjugates to the periplasm of $P$. aeruginosa (Figure 2, G-L). These results are in line with the findings of Nolan and co-workers ${ }^{[41]}$ reporting that $P$. aeruginosa exhibits greater promiscuity for the uptake compared to $E$. coli. Looking at the crystal structure of $\mathrm{PfeA},{ }^{[68]}$ the outer membrane siderophore receptor of $P$. aeruginosa, a similar elliptical inner diameter between $25-35 \AA$ can be assumed. Consistently, none of the corresponding permethylated negative probes led to a growth recovery neither in $E$. coli nor $P$. aeruginosa (see Supporting Information, Figures S3-S8). 


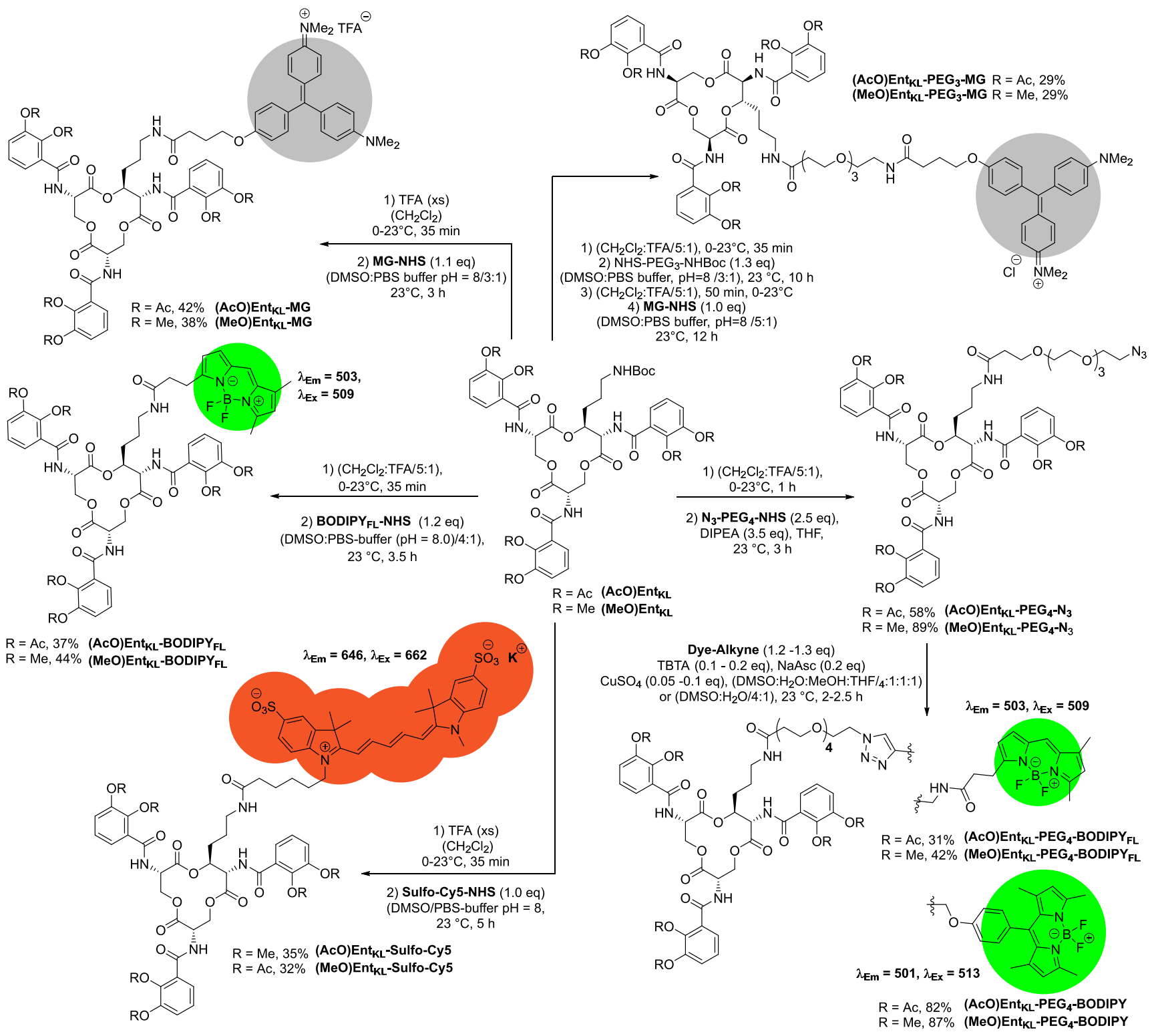

Scheme 4. Synthesis of different Ent $\mathrm{KL}_{\mathrm{L}}$-cargo conjugates bearing different fluorophores and chromophores as payload.

The overall growth recovery response to the added compounds was significantly higher for $P$. aeruginosa K648 $\Delta p v d / p c h$ compared to $E$. coli $\mathrm{K}-12 \Delta$ entA, under non-iron-limiting conditions (Figure 3, B). The comparison of the growth recovery over all tested compounds in $E$. coli revealed a similar effciency of all conjugates compared to the natural siderophore Ent (Figure 3 , A). A similar picture was observed for the growth recovery in $P$. aeruginosa. However, for some of the compounds such as (AcO)Ent ${ }_{\mathrm{KL}}$ and $\left(\mathrm{AcO}^{\mathrm{C}} \mathrm{Ent}_{\mathrm{KL}}-\mathrm{PEG}_{4}\right.$-BODIPY an even improved performance compared to Ent was observed (Figure 3, B).

Furthermore, we were able to demonstrate that growth of $P$. aeruginosa mutants could be restored with (AcO)Ent $\mathrm{KL}_{\mathrm{KL}}$ in the presence of comparably high concentrations $(0.01 \mu \mathrm{M}, 0.1 \mu \mathrm{M}$, $1.0 \mu \mathrm{M}$ and $10 \mu \mathrm{M})$ of the human iron scavenger protein apotransferrin $\left(K_{d}=10^{22}\right)^{[111]}$ (see Supporting Information, Figure S9). Further, an additional growth recovery assay was conducted with (AcO)Ent $\mathrm{KL}_{\mathrm{L}}$ in the presence of high concentrations $(1.0 \mu \mathrm{M}$, $10.0 \mu \mathrm{M}, 50 \mu \mathrm{M}$ and $100 \mu \mathrm{M}$ ) bovine serum albumin (see Supporting Information, Figure S9). It is worth to mention, that growth recovery was achieved with (AcO)Ent $\mathrm{KL}_{\mathrm{L}}$. Albumin is responsible for the transport of lipophilic compounds and it is therefore able to bind Ent $^{[110]}$ These results indicate the potential ability of our designed enterobactin derivative (AcO)Ent $\mathrm{KL}_{\mathrm{KL}}$ to compete with human iron-binding and lipophilic transport serum proteins.

Next, we incubated (AcO)Ent $\mathrm{KL}_{\mathrm{LL}}-\mathrm{BODIPY} \mathrm{FL}_{\mathrm{FL}} \quad(\mathrm{MeO}) \mathrm{Ent}_{\mathrm{KL}}-$ BODIPY $_{\mathrm{FL},}(\mathrm{AcO})$ Ent $_{\mathrm{KL}}-\mathrm{PEG}_{4}-\mathrm{BODIPY}_{\mathrm{FL}}$ and $(\mathrm{MeO})$ Ent $_{\mathrm{KL}}-\mathrm{PEG}_{4}{ }^{-}$ BODIPY $_{\mathrm{FL}}$ at different concentrations with $E$. coli $\mathrm{K}-12 \Delta e n t A$, $P$. aeruginosa $\mathrm{K} 648 \Delta p v d / p c h$ and their corresponding wild-type strains under iron-limiting conditions in order to proof whether uptake of the probes leads to fluorescence labelling of the bacteria. To our delight, all assessed bacteria were fluorescently labelled when treated with either (AcO)Ent $\mathrm{KL}_{\mathrm{KL}}-\mathbf{P E G}_{4}-\mathrm{BODIPY}_{\mathrm{FL}}$ or (AcO)Ent ${ }_{\mathrm{KL}}-\mathrm{BODIPY}_{\mathrm{FL}}$ at concentrations of $10 \mu \mathrm{M}$ (Figure 4, A, $B, D$ and $E$, see Supporting Information, Figures S10, S12, S15 and $\mathrm{S} 17$ ), further confirming the uptake into the wild-type and mutant strains of $E$. coli and $P$. aeruginosa. 


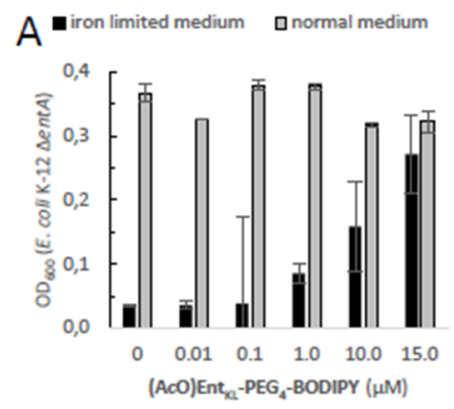

D $\mathbf{\square}$ iron limited medium $\quad$ nnormal medium
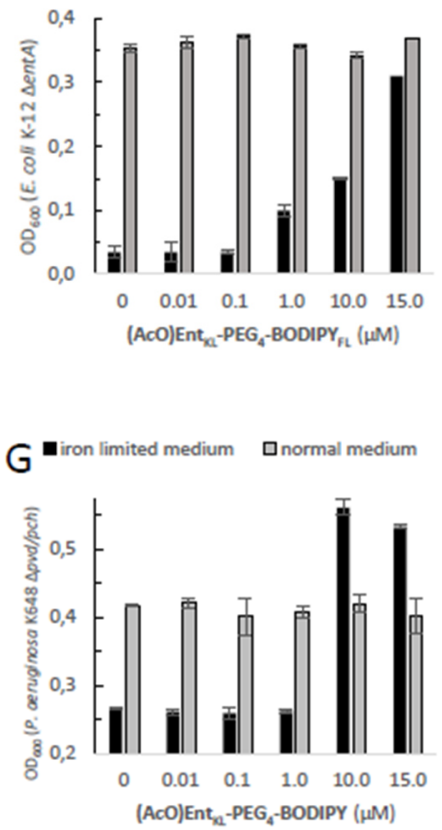

$\mathbf{J} \mathbf{\square}$ iron limited medium anormal medium

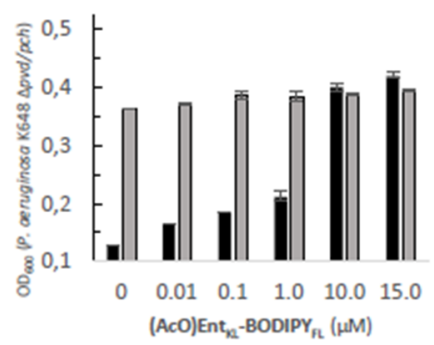

$\mathrm{B}$

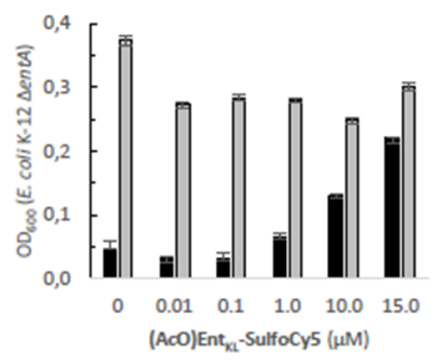

$E$.
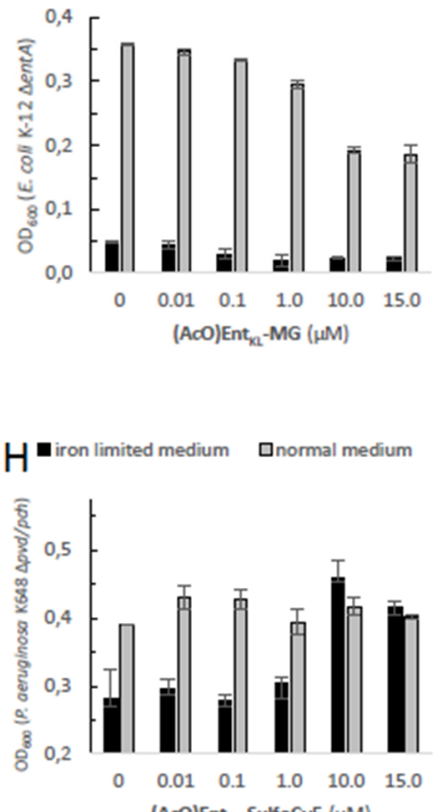

(AcO)Ent ${ }_{\mathrm{ki}}$-SulfoCyS ( $\left.\mu \mathrm{M}\right)$

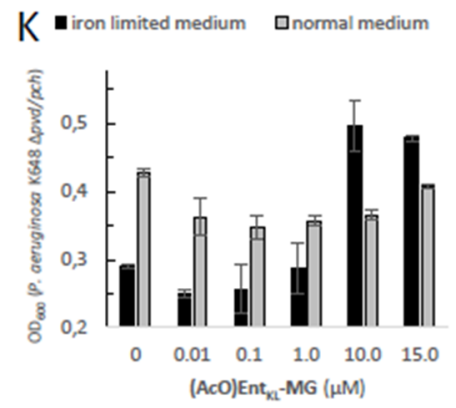

C

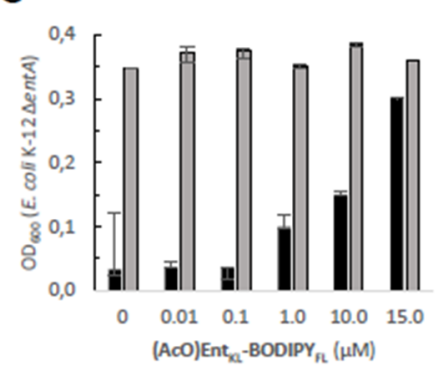

F

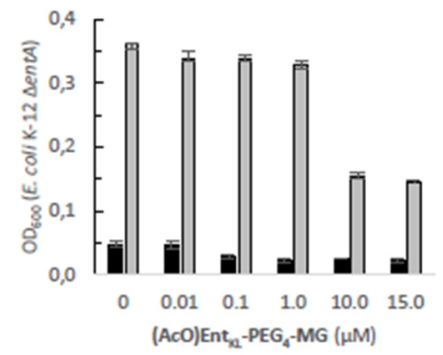

| iron limited medium $\square$ normal medium
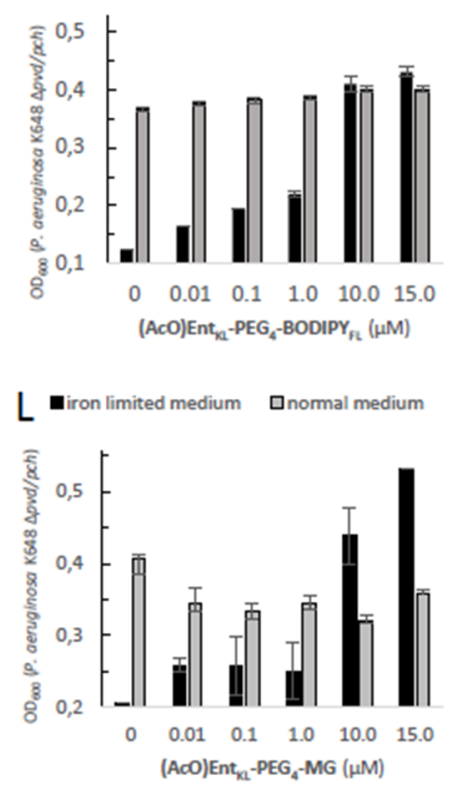

Figure 2. E. coli K-12 $\Delta$ entA (A-F) and $P$. aeruginosa K648 $\Delta$ pvd/pch (G-L) growth recovery assays employing (AcO)Ent KL-PEG $_{4}-\mathrm{BODIPY}_{\mathrm{L}}\left(\mathrm{AcO}_{\mathrm{C}} \mathrm{Ent}_{\mathrm{KL}}-\mathrm{BODIPY}_{\mathrm{FL}}\right.$,

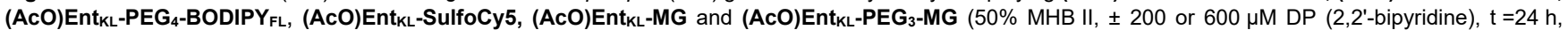
$\left.30^{\circ} \mathrm{C}\right)$. Gray bars: $\mathrm{OD}_{600}$ of bacteria cultured in the absence of DP. Black bars: $\mathrm{OD}_{600}$ of bacteria cultured in the presence of $200 \mu \mathrm{M}(E$. coli) or $600 \mu \mathrm{M}(P$. aeruginosa) DP. A) (AcO)EntкL-PEG4-BODIPY promotes growth recovery of E. coli. B) (AcO)EntKL-SulfoCy5 promotes growth recovery of E. coli. C) (AcO)EntKL-BODIPYFL

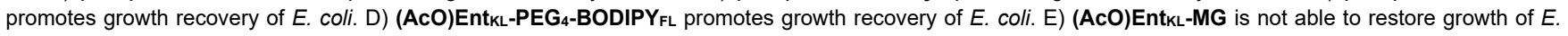
coli. F) (AcO)Ent $\mathrm{KL}_{\mathrm{L}}-\mathrm{PEG}_{3}-\mathbf{M G}$ is not able to restore growth of $E$. coli. G) (AcO)Ent $\mathrm{KL}_{\mathrm{L}}-\mathrm{PEG}_{4}-\mathrm{BODIPY}$ promotes growth recovery of $P$. aeruginosa. $\left.\mathrm{H}\right)(\mathbf{A c O}) \mathrm{Ent}_{\mathrm{KL}}-$ SulfoCy5 promotes growth recovery of $P$. aeruginosa. I) (AcO)Ent $\mathrm{KL}_{\mathrm{L}}-\mathrm{BODIPY}_{\mathrm{FL}}$ promotes growth recovery of $P$. aeruginosa. J) (AcO)Ent $\mathrm{AL}_{\mathrm{KL}}-\mathrm{PEG}_{4}-\mathrm{BODIPY}_{\mathrm{FL}}$ promotes growth recovery of $P$. aeruginosa. K) (AcO)EntKL-MG promotes growth recovery of $P$. aeruginosa. L) (AcO)EntKL-PEG 3 -MG promotes growth recovery of $P$. aeruginosa. Each bar indicates the average of three independent replicates (two wells per replicate) and the error bars are the standard deviation of the mean.

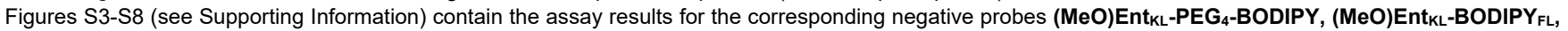

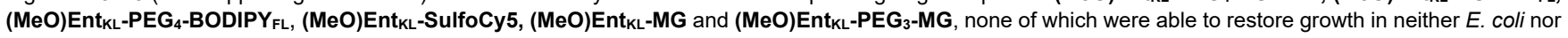
or $P$. aeruginosa

Weaker fluorescence was observed at $1.0 \mu \mathrm{M}$ concentration of the fluorophore conjugates on all tested strains (see Supporting Information, Figures S10, S12, S15 and S17). Furthermore, we observed slight differences in the labeling performance of (AcO)Ent $\mathrm{KL}_{\mathrm{L}}-\mathrm{BODIPY} \mathrm{FL}_{\mathrm{FL}}$ and (AcO)Ent $\mathrm{KL}_{\mathrm{KL}}-\mathrm{PEG}_{4}-\mathrm{BODIPY}_{\mathrm{FL}}$ for the different bacteria. While (AcO)Ent $\mathrm{KL}_{\mathrm{K}}-\mathrm{BODIPY}_{\mathrm{FL}}$ led to more prominent labelling of $E$. coli BW25113 and E. coli K-12 $\Delta$ entA,
(AcO)Ent $\mathrm{KL}_{\mathrm{L}}-\mathrm{PEG}_{4}-\mathrm{BODIPY}_{\mathrm{FL}}$ preferred of $P$. aeruginosa PA01 and $P$. aeruginosa K468 $\Delta p v d / p c h$. Consistently, no labelling was observed when cells were treated with either (MeO)Ent $\mathrm{KL}_{\mathrm{KL}}$ BODIPY $_{\mathrm{FL}}, \quad\left(\mathrm{MeO}\right.$ Ent $_{\mathrm{KL}}-\mathrm{PEG}_{4}-\mathrm{BODIPY}_{\mathrm{FL}}$ or non-conjugated BODIPY $Y_{\mathrm{FL}}$-alkyne alone (see Supporting Information, Figures S11, S13, S14, S16, S18 and S19). 
A
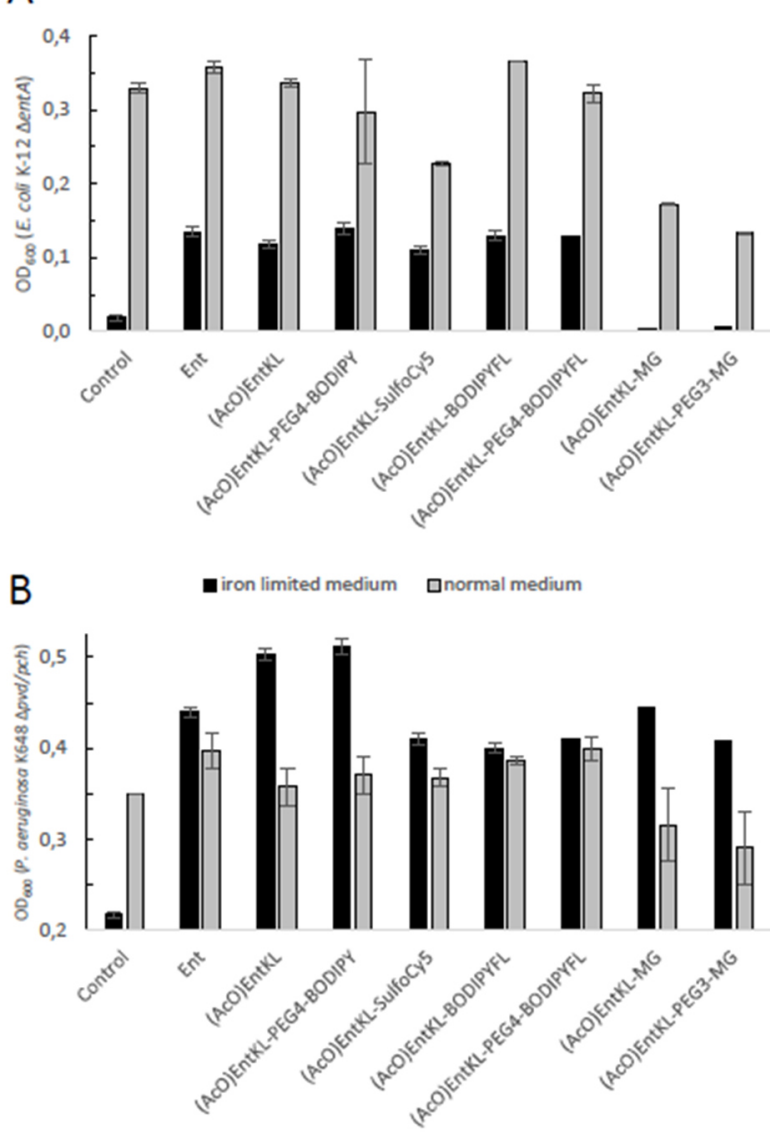

Figure 3. Comparison of $E$. coli $\mathrm{K}-12 \Delta \operatorname{entA}(\mathrm{A})$ and $P$. aeruginosa $\mathrm{K} 648$ $\Delta p v d / p c h(B)$ growth recovery assays employing $10 \mu \mathrm{M}$ concentration of (AcO)Ent $\mathrm{KL}_{\mathrm{KL}} \mathrm{PEG}_{4}$-BODIPY, (AcO)Ent $\mathrm{KL}_{\mathrm{L}}-\mathrm{BODIPY}_{\mathrm{FL}}$, (AcO)Ent $\mathrm{KL}_{\mathrm{KL}}-\mathrm{PEG}_{4}$ BODIPY $_{\mathrm{FL}},(\mathrm{AcO}) \mathrm{Ent}_{\mathrm{KL}}-$ SulfoCy5, (AcO)Ent $\mathrm{KL}_{\mathrm{L}} \mathrm{MG}$ and (AcO)Ent $\mathrm{KL}_{\mathrm{KL}}-\mathrm{PEG}_{3}-\mathrm{MG}$ under iron-limiting and non-limiting conditions $(50 \% \mathrm{MHB} I \mathrm{I}, \pm 200$ or $600 \mu \mathrm{M}$ DP $\left(2,2^{\prime}\right.$-bipyridine $\left.), t=24 \mathrm{~h}, 37^{\circ} \mathrm{C}\right)$. Gray bars: $\mathrm{OD}_{600}$ of bacteria cultured in the absence of DP. Black bars: $\mathrm{OD}_{600}$ of bacteria cultured in the presence of $200 \mu \mathrm{M}$ (E. coli) or $600 \mu \mathrm{M}(P$. aeruginosa) DP. Each bar indicates the average of three independent replicates (two wells per replicate) and the error bars are the standard deviation of the mean.

Fluorescence labeling of $E$. coli $\mathrm{K}-12 \Delta$ ent $A$ and $P$. aeruginosa $\mathrm{K} 468 \Delta p v d / p c h$ was also observed when treating the bacteria with

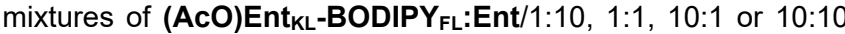
(Figures S20 and S21).

Interestingly, the fluorescence labelling for $E$. coli and $P$. aeruginosa mutant strains seems to be increased in the presence of Ent, as lower concentrations of $1.0 \mu \mathrm{M}$ of the fluorophore conjugates led to strong fluorescence signals (Figure $4, \mathrm{C}$ and $\mathrm{F}$ ). We assume that the overall fitness of the bacteria is increased in the presence of additional siderophore, leading to a more efficient uptake of the fluorophore conjugates.

Finally, (AcO)Ent $\mathrm{KL}_{\mathrm{L}},(\mathrm{MeO}) \mathrm{Ent}_{\mathrm{KL}}$ and all derived cargoconjugates were investigated for their antibacterial activity against the $E$. coli and $P$. aeruginosa strains and the compounds' cytotoxic activity against human HepG2 cells was assessed (see Supporting Information, Table S3). All tested compounds lack antibacterial and cytotoxic activity, which is important looking at (AcO)Ent $\mathrm{KL}_{\mathrm{KL}}$ in the context of being potentially used as safe carrier molecule for the future development of antimicrobial siderophore drug conjugates that help to prevent fast resistance development. In addition, all compounds lack any cytotoxic activity against human HepG2 cells, enabling their possible application in mammalian cells.
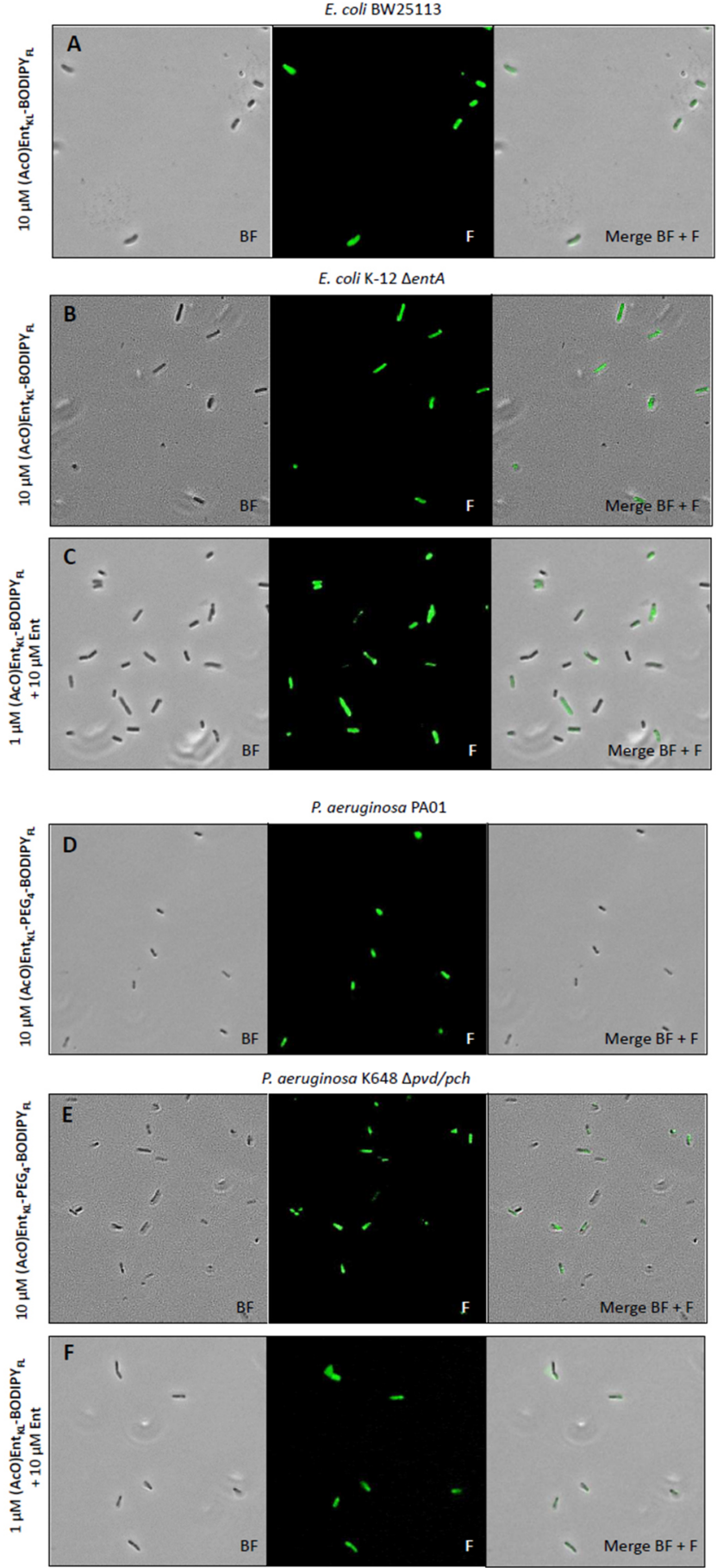

Figure 4. Fluorescence microscopy of $E$. coli BW25113, E. coli K-12 $\Delta$ entA, $P$. aeruginosa $\mathrm{PA} 01$ and $P$. aeruginosa $\mathrm{K} 468 \Delta p c h / p v d$ cultivated under ironlimiting conditions $\left(50 \% \mathrm{MHB} I \mathrm{I},+200\right.$ or $600 \mu \mathrm{M}$ DP $\left(2,2^{\prime}\right.$-bipyridine $), \mathrm{t}=24 \mathrm{~h}$, $37^{\circ} \mathrm{C}$ ) and treated with $10 \mu \mathrm{M}$ of (AcO)Ent $\mathrm{KL}_{\mathrm{KL}}$ BODIPY FL $_{\mathrm{F}}(\mathrm{A}$ and $\mathrm{B}), 10 \mu \mathrm{M}$ of

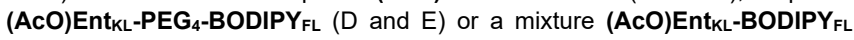
$(1 \mu \mathrm{M})$ : Ent $(10 \mu \mathrm{M})(\mathrm{C}$ and $\mathrm{F})$. All images were captured using a $40 \mathrm{x} / 1.30$ objective (overall magnification of 400x). BF: Bright field, F: Fluorescence GFP filter set (excitation: $480 \mathrm{~nm}, 20 \mathrm{~nm}$ bandwidth; emission: $527 \mathrm{~nm}, 15 \mathrm{~nm}$ bandwidth).

\section{Conclusion}

In summary, we designed and synthesized the novel enterobactin derivative $(\mathbf{A c O}) E_{\text {nt }} \mathrm{KL}_{\text {, }}$ which retains the natural hydrolyzability of the tris-lactone scaffold, while providing an amino handle for easy attachment of cargos in the backbone. In silico studies at the DFT level of theory predicted a high thermodynamic stability combined 
with kinetic lability for the iron (III) complexes similarly as demonstrated earlier for the natural ferri-siderophore [FeEnt] ${ }^{3-}$.

Growth recovery experiments with siderophore biosynthesis deficient mutants of $E$. coli and $P$. aeruginosa under iron-limiting conditions revealed an uptake of $\left(\mathrm{AcO} \mathrm{Ent}_{\mathrm{KL}}\right.$ and other Ent $_{\mathrm{KL}}$-based derivatives into the tested bacteria, while, in

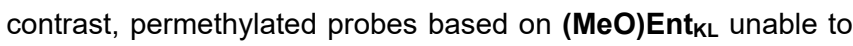
bind iron, did not lead to any growth recovery.

Furthermore, imaging experiments under iron-limiting conditions utilizing $E$. coli and $P$. aeruginosa deficient mutants and wild-type strains showed labelling of the bacteria, further underlining the uptake of cargo conjugates.

As fluorophore uptake into both, E. coli K-12 $\Delta$ entA and $P$. aeruginosa $\mathrm{K} 648 \Delta p v d / p c h$, was increased in the presence of supplemented Ent, we assume that overexpression of Ent would not contribute to any resistance against Ent $_{\mathrm{KL}}$-based drug conjugates.

Since growth recovery was also observed in the presence of high concentrations of human apo-transferrin or albumin and no antimicrobial activity or cytotoxicity was observed, (AcO)Ent KL $_{\mathrm{K}}$ holds potential to serve as good starting point for the assembly of antimicrobial siderophore drug conjugates to tackle infections caused by Gram-negative bacterial pathogens in humans.

Further investigations towards the determination of the size exclusion limit of siderophore receptors and the synthesis of first drug conjugates are ongoing.

\section{Author Contributions}

The research was conceived by P.K. The manuscript was written by P.K. with contributions of R.Z., J.C., J.G. and R.M.. The SI was written by R.Z., P.K., J.C., J.H., J.G. and R.M.. All compounds were synthesized by R.Z.. Computations were planned by J.G. and conducted by J.V. Biological evaluation of the compounds was planned by J.H., R. M., J.C. and P.K. and conducted by J.C.. All authors have given approval to the final version of the manuscript.

\section{Acknowledgements}

This work has been carried out within the framework of the SMART BIOTECS alliance between the Technische Universität Braunschweig and the Leibniz Universität Hannover. This initiative is supported by the Ministry of Science and Culture (MWK) of Lower Saxony, Germany. Financially support by the DFG (Grant KL3012/2-1) and Fonds der Chemischen Industrie is gratefully acknowledged. The content of this work is solely the responsibility of the authors and does not necessarily represent the official views of the funding agencies.

The authors thank Prof. Dr. Mark Brönstrup from the Helmholtz Centre of Infection Research for kindly providing bacterial strains sued in this study. The authors thank the mass spectrometry unit of the Institute of Organic Chemistry at the TU Braunschweig, in particular Dr. Ulrich Papke, the NMR spectroscopy unit of the Institute of Organic Chemistry, in particular Dr. Kerstin Ibrom, for analytical support, Alexandra Amann for support in the biological evaluation of the compounds as well as Claire C. Jimidar, Charity S. G. Ganskow, Dr. Elmira Ghabraie, Prof. Dr. Stefan Schulz and Dr. Anna Luisa Klahn for helpful discussion and proofreading of the manuscript.

\section{Conflict of Interest}

The authors declare no conflicts of interest.

Keywords: enterobactin $\cdot$ siderophore drug conjugates • molecular imaging $\bullet$ cargo delivery $\bullet$ Gram-negative bacteria

[1] P. Klahn, M. Brönstrup, Curr. Top. Microbiol. Immunol. 2016 , 389, 365-417.

[2] V. M. D'Costa, C. E. King, L. Kalan, M. Morar, W. W. L. Sung, C. Schwarz, D. Froese, G. Zazula, F. Calmels, R. Debruyne, et al., Nature 2011, 477, 457-61.

[3] K. M. G. O'Connell, J. T. Hodgkinson, H. F. Sore, M. Welch, G. P. C. Salmond, D. R. Spring, Angew. Chem. Int. Ed. 2013, 52, 10706-10733.

[4] P. Klahn, M. Brönstrup, Nat. Prod. Rep. 2017, 34, 832-885.

[5] U. Theuretzbacher, K. Outterson, A. Engel, A. Karlen, Nat. Rev. Microbiol. 2019, doi:10.1038/s41579-019-0288-0.

[6] H. W. Boucher, G. H. Talbot, D. K. Benjamin, J. Bradley, R. J. Guidos, R. N. Jones, B. E. Murray, R. A. Bonomo, D. Gilbert, Clin. Infect. Dis. 2013, 56, 1685-1694.

[7] H. W. Boucher, G. H. Talbot, J. S. Bradley, J. E. Edwards, D. Gilbert, L. B. Rice, M. Scheld, B. Spellberg, J. Bartlett, Clin. Infect. Dis. 2009, 48, 1-12.

[8] Prioritization of Pathogens to Guide Discovery, Research and Development of New Antibiotics for Drug-Resistant Bacterial Infections, Including Tuberculosis. Geneva: World Health Organization, (WHO/EMP/IAU/2017.12), 2017.

[9] G. Zhou, Q. Shi, X. Huang, X. Xie, Int. J. Mol. Sci. 2015, 16, 21711-21733.

[10] Y.-M. Lin, M. Ghosh, P. A. Miller, U. Möllmann, M. J. Miller, BioMetals 2019, 32, 425-451.

[11] A. V. Cheng, W. M. Wuest, ACS Infect. Dis. 2019, 5, 816-828.

[12] R. C. Hider, X. Kong, Nat. Prod. Rep. 2010, 27, 637-657.

[13] K. N. Raymond, E. A. Dertz, S. S. Kim, Proc. Natl. Acad. Sci. U. S. A. 2003, 100, 3584-3588.

[14] T. C. Johnstone, E. M. Nolan, Dalton Trans. 2015, 44, 632039.

[15] V. I. Holden, M. A. Bachman, Metallomics 2015, 7, 986-995.

[16] P. Saha, B. S. Yeoh, R. A. Olvera, X. Xiao, V. Singh, D. Awasthi, B. C. Subramanian, Q. Chen, M. Dikshit, Y. Wang, et al., J. Immunol. 2017, 198, 4293-4303.

[17] J. Behnsen, M. Rafatellu, MBio 2016, 7, e01906-16.

[18] V. Braun, M. Braun, FEBS Lett. 2002, 529, 78-85.

[19] P. E. Klebba, Front. Biosci. 2003, 8, 1422-1436.

[20] L. Ma, W. Kaserer, R. Annamalai, D. C. Scott, B. Jin, X. Jiang, Q. Xiao, H. Maymani, L. M. Massis, L. C. S. Ferreira, et al., J. Biol. Chem. 2007, 282, 397-406.

[21] C. R. Smallwood, L. Jordan, V. Trinh, D. W. Schuerch, A. Gala, M. Hanson, Y. Shipelskiy, A. Majumdar, S. M. C. Newton, P. E. Klebba, J. Gen. Physiol. 2014, 144, 71-80.

[22] A. S. Skwarecki, S. Milewski, M. Schielmann, M. J. Milewska, Nanomedicine Nanotechnology, Biol. Med. 2016, 12, 22152240.

[23] C. Ji, R. E. Juárez-Hernández, M. J. Miller, Future Med. Chem. 2012, 4, 297-313.

[24] Curr. Top. Microbiol. Immunol. 2016.

[25] M. G. P. Page, Ann. N. Y. Acad. Sci. 2013, 1277, 115-126.

[26] K. Li, W. H. Chen, S. D. Bruner, BioMetals 2016, 29, 377-388.

[27] K. H. Negash, J. K. S. Norris, J. T. Hodgkinson, Molecules 2019, $24,3314$.

[28] I. J. Schalk, Clin. Microbiol. Infect. 2018, 10.1016/J.CMI.2018.03.037.

[29] V. Braun, A. Pramanik, T. Gwinner, M. Köberle, E. Bohn, BioMetals 2009, 22, 3-13.

[30] H. Budzikiewicz, Curr Top Med Chem 2001, 1, 73-82.

[31] A. Górska, A. Sloderbach, M. P. Marszałt, Trends Pharmacol. Sci. 2014, 1-8.

[32] T. A. Wencewicz, M. J. Miller, in Antibacterials. Topics in Medicinal Chemistry, Vol 26. (Eds.: J. Fisher, S. Mobashery, M.J. Miller), Springer, Cham, 2017. 
[33] V. Braun, K. Gunthner, K. Hantke, L. Zimmermann, J. Bacteriol. 1983, 156, 308-315.

[34] A. Hartmann, H.-P. Fiedler, V. Braun, Eur. J. Biochem. 1979, 99, 517-24.

[35] A. Pramanik, V. Braun, J. Bacteriol. 2006, 188, 3878-3886.

[36] E. M. Nolan, C. T. Walsh, Biochemistry 2008, 47, 9289-9299.

[37] S. Duquesne, D. Destoumieux-Garzón, J. Peduzzi, R. S., Nat. Prod. Rep. 2007, 24, 708-734.

[38] D. Destoumieux-Garzón, J. Peduzzi, X. Thomas, C. Djediat, S. Rebuffat, BioMetals 2006, 19, 181-191.

[39] X. Thomas, D. Destoumieux-Garzón, J. Peduzzi, C. Afonso, A. Blond, N. Birlirakis, C. Goulard, L. Dubost, R. Thai, J. C. Tabet et al., J. Biol. Chem. 2004, 279, 28233-28242.

[40] J. D. Palmer, B. M. Mortzfeld, E. Piattelli, M. W. Silby, B. A. McCormick, V. Bucci, ACS Infect. Dis. 2020, 6, 672-679.

[41] T. Zheng, J. L. Bullock, E. M. Nolan, J. Am. Chem. Soc. 2012 , 134, 18388-18400.

[42] T. Zheng, E. M. Nolan, J. Am. Chem. Soc. 2014, 136, 96779691.

[43] T. A. Wencewicz, U. Möllmann, T. E. Long, M. J. Miller, BioMetals 2009, 22, 633-648.

[44] M. J. Miller, A. J. Walz, H. Zhu, C. Wu, G. Moraski, U. Möllmann, E. M. Tristani, A. L. Crumbliss, M. T. Ferdig, L. Checkley, et al., J. Am. Chem. Soc. 2011, 133, 2076-2079.

[45] W. Neumann, E. M. Nolan, J. Biol. Inorg. Chem. 2018, 23, 1025-1036.

[46] H. Kong, W. Cheng, H. Wei, Y. Yuan, Z. Yang, X. Zhang, Eur. J. Med. Chem. 2019, 182, 111615.

[47] C. Ji, P. A. Miller, M. J. Miller, J. Am. Chem. Soc. 2012, 134, 9898-9901.

[48] P. Chairatana, T. Zheng, E. M. Nolan, Chem. Sci. 2015, 6, 4458-4471.

[49] M. Ghosh, Y.-M. Lin, P. A. Miller, U. Möllmann, W. Boggess, M. J. Miller, ACS Infect. Dis. 2018, 4, 1529-1535.

[50] M. Ghosh, P. A. Miller, U. Möllmann, W. D. Claypool, V. A. Schroeder, W. R. Wolter, M. Suckow, H. Yu, S. Li, W. Huang et al., J. Med. Chem. 2017, 60, 4577-4583.

[51] W. Neumann, M. Sassone-Corsi, M. Raffatellu, E. M. Nolan, J. Am. Chem. Soc. 2018, 140, 5193-5201.

[52] W. Neumann, E. M. Nolan, J. Biol. Inorg. Chem. 2018, 23, 1025-1036.

[53] T. A. Wencewicz, T. E. Long, U. Möllmann, M. J. Miller, Bioconjug Chem 2013, 24, 473-486.

[54] S. Wittmann, M. Schnabelrauch, I. Scherlitz-Hofmann, U. Möllmann, D. Ankel-Fuchs, L. Heinisch, Bioorganic Med. Chem. 2002, 10, 1659-1670.

[55] M. Ghosh, P. A. Miller, M. J. Miller, J. Antibiot. 2019 , 10.1038/s41429-019-0268-7.

[56] R. Liu, P. A. Miller, S. B. Vakulenko, N. K. Stewart, W. C. Boggess, M. J. Miller, J. Med. Chem. 2018, 61, 3845-3854.

[57] M. G. P. Page, Clin. Infect. Dis. 2019, 69, S529-S537.

[58] R. C. Scarrow, D. J. Ecker, C. Ng, S. Liu, K. N. Raymond, Inorg. Chem. 1991, 30, 900-906.

[59] L. D. Loomis, K. N. Raymond, Inorg. Chem. 1991, 30, 906-911.

[60] S. I. Müller, M. Valdebenito, K. Hantke, BioMetals 2009, 22, 691-695.

[61] M. A. Fischbach, H. Lin, D. R. Liu, C. T. Walsh, Nat. Chem. Biol. 2006, 2, 132-138.

[62] C. Guo, L. K. Steinberg, M. Cheng, J. H. Song, J. P. Henderson, M. L. Gross, ACS Chem. Biol. 2020, 15, 1154-1160.

[63] S. M. Payne, I. B. Neilands, Crit. Rev. Microbiol. 1988, 16, 81111.

[64] H. P. Fiedler, P. Krastel, J. Müller, K. Gebhardt, A. Zeeck, FEMS Microbiol. Lett. 2001, 196, 147-151.

[65] B. Ghysels, U. Ochsner, U. Möllman, L. Heinisch, M. Vasil, P. Cornelis, S. Matthijs, FEMS Microbiol. Lett. 2005, 246, 167174.

[66] K. Poole, L. Young, S. Neshat, J. Bacteriol. 1990, 172, 6991_ 6996.

[67] C. R. Dean, S. Neshat, K. Poole, J. Bacteriol. 1996, 178, 5361_ 5369.

[68] L. Moynié, S. Milenkovic, G. L. A. Mislin, V. Gasser, G. Malloci,
E. Baco, R. P. Mccaughan, M. G. P. Page, I. J. Schalk, M. Ceccarelli, et al., Nat. Commun. 2019, 10, 3673.

[69] W. Zhu, M. G. Winter, L. Spiga, D. P. Beiting, L. V Hooper, S. E. Winter, W. Zhu, M. G. Winter, L. Spiga, E. R. Hughes, et al., Cell Host Microbe 2020, 27, 1-13.

[70] M. Petrik, C. Zhai, H. Haas, C. Decristoforo, Clin. Transl. Imaging 2017, 5, 15-27.

[71] R. Nosrati, S. Dehghani, B. Karimi, M. Yousefi, S. M. Taghdisi, K. Abnous, M. Alibolandi, M. Ramezani, Biosens. Bioelectron. 2018, 117, 1-14.

[72] A. A. Lee, Y. S. Chen, E. Ekalestari, S. Ho, N. Hsu, T. Kuo, T. A. Wang, Angew Chem Int Ed Engl 2016, 55, 12338-12342.

[73] K. Ferreira, H. Y. Hu, V. Fetz, H. Prochnow, B. Rais, P. P. Müller, M. Brönstrup, Angew. Chem. Int. Ed. 2017, 56, 82728276.

[74] M. Schnabelrauch, S. Wittmann, K. Rahn, U. Möllmann, R. Reissbrodt, L. Heinisch, BioMetals 2000, 13, 333-348.

[75] C. Y. Zamora, A. G. E. Madec, W. Neumann, E. M. Nolan, B. Imperiali, Bioorganic Med. Chem. 2018, 26, 5314-5321.

[76] S. K. Buchanan, B. S. Smith, L. Venkatramani, D. Xia, L. Esser, M. Palnitkar, R. Chakraborty, D. Van Der Helm, J. Deisenhofer, Nat. Struct. Biol. 1999, 6, 56-63.

[77] W. Rabsch, W. Voigt, R. Reissbrodt, R. M. Tsolis, A. J. Bäumler, J. Bacteriol. 1999, 181, 3610-3612.

[78] K. Hantke, G. Nicholson, W. Rabsch, G. Winkelmann, Proc. Natl. Acad. Sci. U. S. A. 2003, 100, 3677-3682.

[79] T. A. Russo, C. D. McFadden, U. B. Carlino-MacDonald, J. M. Beanan, T. J. Barnard, J. R. Johnson, Infect. Immun. 2002, 70, 7156-7160.

[80] T. C. Johnstone, E. M. Nolan, J. Am. Chem. Soc. 2017, 139, 15245-15250

[81] F. Peuckert, M. Miethke, A. G. Albrecht, L. O. Essen, M. A Marahiel, Angew. Chem. Int. Ed. 2009, 48, 7924-7927.

[82] F. Peuckert, A. L. Ramos-Vega, M. Miethke, C. J. Schwörer, A. G. Albrecht, M. Oberthür, M. A. Marahiel, Chem. Biol. 2011, 18, 907-919.

[83] X. Liu, Q. Du, Z. Wang, S. Liu, N. Li, Y. Chen, C. Zhu, D. Zhu T. Wei, Y. Huang, et al., FEBS Lett. 2012, 586, 1240-1244.

[84] R. J. Abergel, A. M. Zawadzka, T. M. Hoette, K. N. Raymond, J. Am. Chem. Soc. 2009, 131, 12682-12692.

[85] A. Shanzer, J. Libman, S. Lifson, C. E. Felder, J. Am. Chem. Soc. 1986, 108, 7609-7619.

[86] A. Shanzer, J. Libman, J. Chem. Soc. Chem. Commun. 1983 846-847.

[87] R. J. A. Ramirez, L. Karamanukyan, S. Ortiz, C. G. Gutierrez, Tetrahedron Lett. 1997, 38, 749-752.

[88] M. Meyer, J. R. Telford, S. M. Cohen, D. J. White, J. Xu, K. N. Raymond, R. V March, J. Am. Chem. Soc. 1997, 119, 1009310103.

[89] E. J. Corey, S. Bhattacharyya, Tetrahedron Lett 1977, 39193922.

[90] W. H. Rastetter, T. J. Erickson, M. C. Venuti, J. Org. Chem. 1981, 45, 3579-3590.

[91] H. J. Rogers, J. Chem. Soc., Perkin Trans. 1 1995, 3073-3075.

[92] T. Baramov, B. Schmid, H. Ryu, J. Jeong, K. Keijzer, L. von Eckardstein, M. H. Baik, R. D. Süssmuth, Chem. - A Eur. J. 2019, 25, 6955-6962.

[93] K. Brandhorst, J. Grunenberg, J. Chem. Phys. 2010, 132, 184101.

[94] M. D. Walter, J. Grunenberg, P. S. White, Chem. Sci. 2011, 2, 2120-2130.

[95] J. Grunenberg, N. Goldberg, J. Am. Chem. Soc. 2000, 122, 6045-6047.

[96] J. Grunenberg, Chem. Sci. 2015, 6, 4086-4088.

[97] J. Grunenberg, Angew. Chemie 2017, 129, 7394-7397.

[98] S. S. Isied, G. Kuo, K. N. Raymond, J. Am. Chem. Soc. 1976, 98, 1763-1767.

[99] A. Avdeef, S. R. Sofen, T. L. Bregante, K. N. Raymond, J. Am. Chem. Soc. 1978, 100, 5362-5370.

[100] J. A. Dale, D. L. Dull, H. S. Mosher, J. Org. Chem. 1969, 34, 2543-2549.

[101] K. C. Nicolaou, A. A. Estrada, M. Zak, S. H. Lee, B. S. Safina, 
Angew. Chemie Int. Ed. 2005, 44, 1378-1382.

[102] I. Shiina, R. Ibuka, M. Kubota, Chem. Lett. 2002, 286-287.

[103] J. Inanaga, K. Hirata, H. Saeki, T. Katsuki, M. Yamaguchi, Bull. Chem. Soc. Jpn. 1979, 52, 1989-1993.

[104] H. Gerlach, A. Thalmann, Helv. Chim. Acta 1974, 57, 26612663.

[105] E. J. Corey, K. C. Nicolaou, J. Am Chem. Soc 1974, 96, 56145616.

[106] U. Möllmann, L. Heinisch, A. Bauernfeind, T. Köhler, D. AnkelFuchs, Biometals 2009, 22, 615-624.

[107] N. Ohi, B. Aoki, T. Kuroki, M. Matsumoto, K. Kojima, T. Nehashi, $J$ Antibiot 1987, 40, 22-28.

[108] N. Sukhbaatar, T. Weichhart, Pharmaceuticals 2018, 11, 137.

[109] T. Ganz, Int. J. Hematol. 2018, 107, 7-15.

[110] Q. Perraud, P. Cantero, B. Roche, V. Gasser, Mol. Cell. Proteomics 2020, 0.1074/mcp.RA119.001829.

[111] P. Aisen, I. Listowsky, Annu. Rev. Biochem. 1980, 49, 357-393.

[112] J. B. Neilands, K. Konopka, Biochemistry 1984, 23, 2122-2127. 